IN PRACTICE

\title{
Patterns of uptake of treatment for self reported sexually transmitted infection symptoms in rural Zimbabwe
}

\author{
J J C Lewis, G P Garnett, C A Nyamukapa, C A Donnelly, P R Mason, S Gregson
}

Sex Transm Infect 2005;81:326-332. doi: 10.1136/sti.2004.012773

See end of article for authors' affiliations

.....................

Correspondence to: James J C Lewis,

Department of Infectious Disease Epidemiology, Imperial College London, Faculty of Medicine, St Mary's Campus, Norfolk Place, London W2 IPG, UK; james.lewis@imperial. ac.uk

Accepted for publication 5 October 2004

\begin{abstract}
Objectives: To determine the extent of self reported symptoms perceived to be related to sexually transmitted infections and the patterns of subsequent treatment seeking behaviour in a predominantly rural population of Zimbabwe.

Methods: A population based survey of 4331 men and 5149 women was conducted in rural Zimbabwe during 1998-2000. Structured confidential interviews collected data on self reported sexually transmitted infection symptoms, treatment seeking behaviour, sociodemographic characteristics, and sexual behaviour.

Results: $25 \%$ of men aged 17-54 years report experiencing genital sores and $25 \%$ of men report experiencing urethral discharge; 30\% of women aged 15-44 years report experiencing vaginal discharge. The lifetime number of sexual partners, age, and years of sexual activity were all significant predictors of symptoms for both men and women (all $p$ values $<0.001$ ). $92 \%$ of men and $62 \%$ of women had sought treatment for their symptoms in the past year ( $p$ value $<0.001$ ). Men and women were equally likely to have sought treatment at a local hospital or clinic, but women were much less likely than men to have sought treatment at a different hospital or clinic. Among those who had sought treatment, men sought treatment faster than women and were more likely to report being "very satisfied" with their treatment than women.

Conclusions: The gender differences in treatment seeking are of major concern for control efforts and further work on determining the reasons for these should be a priority. This would inform the likely impact of both increasing availability of local services and further reducing the stigma faced by those wishing to access such services.
\end{abstract}

Z imbabwe has one of the highest HIV prevalences globally, with an estimated $25 \%$ of adults currently infected. ${ }^{1}$ There were 727788 diagnoses of sexually transmitted infections (STIs) reported to the Ministry of Health in $1999^{2}$ in an adult (15-49 years) population of 6.0 million. ${ }^{3}$ This is particularly important given the increased susceptibility to HIV infection attributed to the presence of STIs. ${ }^{45}$ High HIV and STI prevalences are not restricted to the urban centres. The Manicaland population prevalence survey, conducted in predominantly rural areas, found adult HIV prevalences of $19 \%$ for men (17-44 years) and 26\% for women (15-44 years). ${ }^{6}$ Pilot study testing for other STIs in neighbouring rural areas found high herpes simplex virus type 2 (HSV-2) prevalences $(53 \%$ of men and $67 \%$ of women), substantial prevalence of trichomoniasis (4\% of men and 13\% of women), and prevalences of gonorrhoea, chlamydia, and syphilis all less than $3 \%{ }^{7}$ This paper describes the levels of self reported symptoms presumed to be related to STIs in the Manicaland population survey, relates these to HIV infection and sexual behaviour, and then describes patterns in uptake of available services for STI treatment.

Timely and appropriate treatment of bacterial STIs is a crucial public health goal preventing progress to disease in the individual and also reducing the onward spread of infection. As the fraction of symptomatic cases rapidly cured increases then the incidence of new infections will decline to a lower limit imposed by the presence of asymptomatic infections, which require alternative control strategies. ${ }^{8}$ In resource poor settings treatment has to be based on syndromic diagnosis rather than using laboratory tests to identify aetiological agents. This leads to some overtreatment, but if appropriate clinical algorithms are used, should lead to expedited, efficacious care. ${ }^{9}$ In determining how effective basic STI management is locally, the population's recognition of symptoms, timeliness of seeking care, and location from which it is sought need to be assessed along with the care provided. ${ }^{10}$ Studies in industrialised countries of patients attending sexually transmitted disease clinics have explored the duration of symptoms before treatment, ${ }^{11}{ }^{12}$ but fail to capture those who do not seek care or seek alternative sources of care. Population based surveys of self reported symptom history and the care provided can be used to understand patterns of treatment seeking behaviour. Self identified syndromes clearly do not address issues of symptom recognition in the absence of concomitant surveys for signs and aetiological agents. None the less, it is possible to see how well reports of symptom history correlate with known risk factors, and more importantly, current patterns of treatment seeking for symptoms should inform health education and healthcare provision. In sub-Saharan Africa, a study in Mwanza, Tanzania, estimated that 39\% of men and women with STI symptoms sought care before an improvement in services raised this to between $51 \%$ and $72 \%$, with an estimated increase in cure rates from $10 \%$ to between $23 \%$ and $41 \% .^{13}$ A community based study in rural Uganda found that $56 \%$ of those with symptoms sought care and that $67 \%$ of this was probably or possibly effective. ${ }^{14}$

\section{SUBJECTS AND METHODS}

Study populations and data collection procedures

A stratified population based survey was carried out in the Manicaland province in Zimbabwe between July 1998 and January 2000. The population strata comprised 12 distinct

Abbreviations: HSV-2, herpes simplex virus type 2; ICVI, informal, confidential voting interview; STIs, sexually transmitted infections 
communities: two forestry plantations, two tea and coffee estates, four subsistence farming areas, two small towns, and two roadside business areas. A preliminary household census enumerated 8233 of 8386 (98\%) known households in the study areas. One partner within any given marital grouping in a household was invited to participate in the survey. In total, 4331 men aged 17-54 years and 5149 women aged $15-44$ years agreed to participate $(77 \%$ of those eligible).

The survey collected structured data on self reported STI symptoms of urethral/vaginal discharge for men and women and genital sores for men only, both in the past year and in the respondents' lifetime. For those with self reported STI symptoms in the past year, additional data were collected on whether or not assistance was sought and if so, where, the time delay between first noticing symptoms and seeking treatment, and satisfaction with treatment received. All respondents who had experienced any form of illness in the past month were asked for the main symptom and where treatment was sought. Additional data on HIV serostatus, sociodemographics, and sexual behaviour were collected. Interviews were conducted face to face by trained, social science graduates from outside the study areas, but familiar with the local culture. Particularly sensitive questions on sexual behaviour were asked using an informal, confidential voting interview method (ICVI) to reduce social desirability bias, in three quarters of the interviews (selected at random) with literate respondents. ${ }^{15}$

Written informed consent was a condition of enrolment and free voluntary HIV counselling and testing was made available in each study area. Previous ethical approval for the study was obtained from the Research Council of Zimbabwe and from the St Mary's local research ethics committee, London.


Figure 1 The age distributions for men (A) and women (B) of HIV prevalence (solid diamond); self reported genital sores in past 12 months (open circle, broken line) and ever (open circle, solid line); and self reported urethral/vaginal discharge in 12 months (solid square, broken line), and ever (solid square, solid line).
Dried blood spot specimens were collected for HIV testing. A dipstick dot immunoassay with $99.6 \%$ sensitivity and specificity was used to detect the presence of antibodies to HIV. ${ }^{16}$

\section{Data analysis}

Data entry and validation used custom made forms in SPSSPC version 5.0, while data analysis was carried out in SPSSPC version 11.5 and S-PLUS 6.0 Professional Release 2. $\chi^{2}$ tests were used to determine bivariate associations between nominal and binary variables. Univariate and multivariate logistic regressions were used to determine predictors of seeking treatment. Predictors that consisted of counting data were divided into a small number of categories-for example, lifetime number of sexual partners were recoded as $\{0,1,2-3$, $4-10,>10\}$ and then used as nominal variables. The age variable was divided into categories of 15-16, 17-19, 20-24, $25-29,30-34,35-39,40-44,45-49$, and 50-54 years. Age of respondent was an important variable in most analyses; hence, important comparisons between men and women were restricted to those aged 17-44 years rather than the full sample ranges of 15-44 years for women and 17-54 years for men, which are not comparable. Symptoms of illness in the past month were categorised as infectious disease (split into STIs and non-STIs), accidents, chronic conditions, pregnancy related, and other. Associations between the time to seek treatment and variables of interest were assessed using survival analysis, with those who had not sought treatment for symptoms in the past year regarded as censored at 6 months (as symptoms had been experienced at some time in the past year). Log rank tests were used to assess significance of these associations, with the assumption of proportional hazards verified by observation of Kaplan-Meier curves.

\section{RESULTS}

\section{Patterns of STI symptoms and HIV prevalence}

Reported experience of urethral/vaginal discharge and HIV prevalence for men and women, along with genital sores for men, by age is shown in figure 1 . The percentage having ever experienced STI symptoms increases linearly with age, reaching a plateau. Beyond the age of 35 years for men and 25 years for women, the reported experience of discharge was statistically equivalent across the 5 year age categories, similarly for reported experience of sores in men beyond



Figure 2 The proportions ever experiencing an STI symptom as a function of numbers of lifetime sexual partners for men aged 1754 years and women aged 15-44 years: discharge only (dark shading), sores only (light shading), sores and discharge (solid), or no symptoms (open). 
the age of 30 years (all p values $>0.1$ ). It is not likely that this plateau represents a cessation of risk, since $18.3 \%$ of men aged $35-54$ years and $68.9 \%$ of women aged $25-44$ years who had ever experienced discharge had also experienced it in the past year and $46.0 \%$ of men aged 30-54 years who had ever experienced sores had also experienced them in the past year (fig 1).

Men who had experienced sores were significantly more likely to have experienced discharge (OR $=4.7,95 \% \mathrm{CI}: 4.0$ to 5.5).

HIV prevalence rises by age in a similar way to experience of STI symptoms, until 30-34 years for men and 25-34 years for women, after which it declines substantially (fig 1). There was a strong positive association between being HIV infected and having ever experienced STI symptoms, for both urethral/vaginal discharge (men $\mathrm{OR}=5.2,95 \% \mathrm{CI}$ : 4.4 to 6.1; women $\mathrm{OR}=2.3,95 \% \mathrm{CI}: 2.0$ to 2.7 ) and genital sores $(\mathrm{OR}=6.4,95 \% \mathrm{CI}: 5.4$ to 7.6$)$. This relation remained after controlling for age, lifetime partner numbers, years since sexual debut, and marital status, with adjusted odds ratios for HIV infection associated with urethral discharge $(\mathrm{OR}=2.0,95 \% \mathrm{CI}$ : 1.6 to 2.4$)$; vaginal discharge $(\mathrm{OR}=1.5$, 95\% CI: 1.3 to 1.8 ) and genital sores (OR $=2.8,95 \%$ CI: 2.3 to $3.4)$.

\section{Sexual behaviour and STI symptoms}

Figure 2 shows the relation between having ever experienced STI symptoms and the lifetime number of sexual partners for both men and women. The percentage of men who report experiencing symptoms increased steadily with increasing numbers of lifetime partners, from only $1.4 \%$ of men reporting no lifetime partners having experienced some form of symptoms, to $73.8 \%$ of those with more than 10 lifetime partners. The pattern for women was less obvious, with $6.8 \%$ of those reporting no lifetime partners still reporting symptoms, followed by a jump to $31.6 \%$ of those reporting only one lifetime partner, and $60.7 \%$ of those with more than 10 lifetime partners.

Multivariate logistic regressions of lifetime odds of urethral discharge and sores in men and vaginal discharge in women on lifetime number of partners (coded as 0, 1, 2-3, 4-10, $>10$ ), age category and the interaction between the two, found highly significant associations with both lifetime number of partners and age for each of the three outcomes (all p values $<0.001$ ), but not with the interaction (all $\mathrm{p}$ values $>0.1$ ). When the interaction term was removed, both age and lifetime partners remained highly significant (all p values $<0.001$ ). The age adjusted odds ratios for sores and/or discharge for men and discharge for women, with no lifetime partner as baseline were 3.2 and 4.4 for one lifetime partner, 8.0 and 6.1 for two to three lifetime partners, 19.7 and 8.8 for four to 10 lifetime partners, and 38.9 and 14.1 for greater than 10 lifetime partners, respectively. For those who reported at least one lifetime partner, the respondent's age, lifetime partners, and years since sexual debut (5 year categories) were highly significant in predicting odds of all three symptoms ( $p$ values $<0.001$ ).

\section{Treatment seeking behaviour for STI symptoms}

One quarter of men and three quarters of women who had ever experienced urethral/vaginal discharge also reported experiencing these symptoms in the past year, while over half of men who had ever experienced genital sores had also experienced them in the past year. These high infection rates may be indicative of substantial re-infection or prolonged infection with common recurrence of symptoms. Some insight into the likely mechanisms can be derived by considering treatment seeking behaviour (fig 3).
Treatment seeking for any disease symptoms in past month

Similar percentages of men and women, aged 17-44 years, reported non-STI infectious diseases in the past month (18\% versus $19 \%$, p value $=0.202$ ), but men were more likely to have reported STI illness than women ( $2 \%$ versus $1 \%$, p value $=0.014)$. Figure $3 \mathrm{~A}$ shows the distributions of assistance seeking for men and women, for STIs and other infectious diseases separately. There was no difference between men and women in treatment seeking for STIs or other infectious diseases ( $p$ values $=0.395,0.224$ respectively). Two per cent had sought assistance from an n'anga (traditional healer) or faith healer, while $26 \%$ had not sought assistance from anyone. Of the 73 people in the "other" category, 25 had been to a pharmacy, all of whom were seeking help for other infectious diseases and only nine had been to a private doctor, representing $1.5 \%$ and $0.5 \%$ of all those who experienced infectious diseases, including STIs, in the past month respectively.

\section{Treatment seeking for those who experienced STI} symptoms in past year

Treatment seeking behaviour differed between men and women, aged 17-44 years, who had experienced urethral/ vaginal discharge or genital sores in the past year (fig 3B) (p value $<0.001$ ). A comparison of men and women who had only experienced urethral/vaginal discharge showed that women were just as likely to go to their local hospital/clinic as men ( $p$ value $=0.834$ ), but far less likely to go to a different hospital/clinic, with $38 \%$ of women not seeking assistance from anyone, compared to only $8 \%$ of men ( $p$ value $<0.001)$. The treatment seeking pattern for men differed by symptoms experienced, with those experiencing both sores and discharge significantly more likely to have sought treatment at a local hospital/clinic, than those who had experienced only one symptom (sores and discharge; sores only; discharge only: $\mathrm{p}$ value $=0.014$ ).

Men sought treatment for STI symptoms faster than women (fig 3C), with $68 \%$ of men seeking treatment in a week or less, compared to only $35 \%$ of women (log rank test: $\mathrm{p}$ value $<0.001)$. There were no significant differences between the time distributions for men who experienced different symptoms (log rank test: p value $=0.844$ ). These analyses included those who had yet to seek treatment; if these people were removed from the analysis, then men still sought treatment significantly faster than women (log rank test: $\mathrm{p}$ value $<0.001$ )

Among those who experienced symptoms in the past year and had started sex (table 1), men and women aged 1724 years were significantly less likely to have sought treatment for most recent symptoms than those aged 2544 years $(\mathrm{p}$ values $=0.001,0.004$ respectively). Men who had never married were also less likely to have sought treatment than those currently or previously married $(\mathrm{p}$ value $=0.026)$, while for women there was no statistical difference $(p$ value $=0.149)$. However, women who reported a greater number of lifetime sexual partners, a possible indication of past infection or knowledge of risk, were more likely to have sought treatment, but there was no significant difference for men ( $\mathrm{p}$ values $=0.020,0.350$ ). While there was no significant association for men between seeking treatment and knowledge of STIs as co-factors for HIV transmission ( $\mathrm{p}$ value $=0.436$ ), those women who thought it was a co-factor were less likely to have sought treatment ( $p$ value $=0.041$ ). In the multivariate analysis, marital status, number of lifetime partners and STIs as co-factors for HIV transmission were not associated with treatment for either men or women $(\mathrm{p}$ values $>0.1)$. Women who were in 


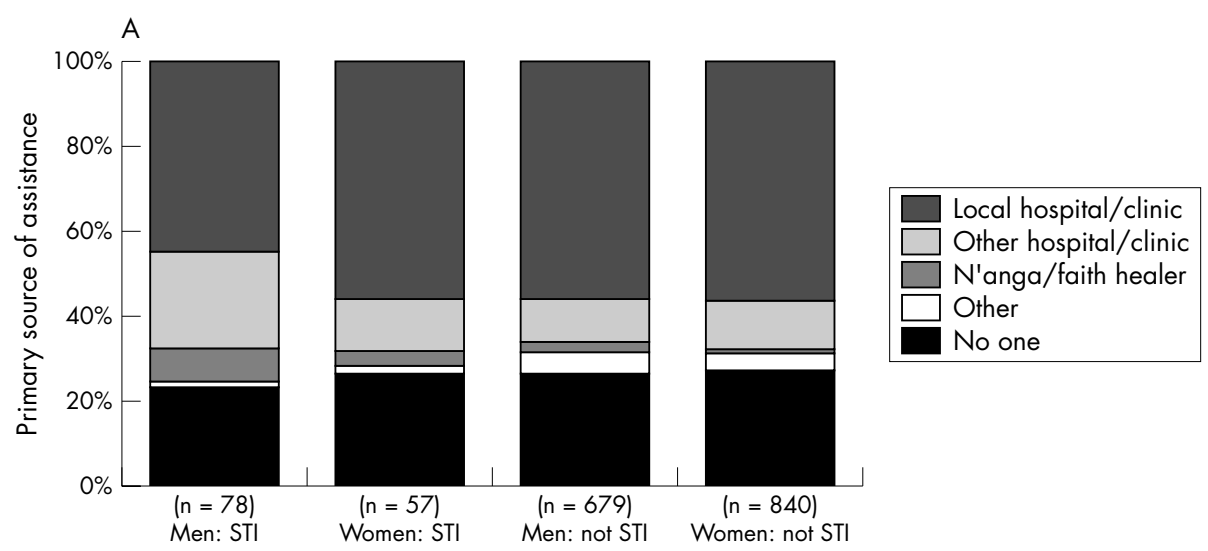

Figure 3 Sources of assistance for men and women (aged 17-44 years) who experienced $(A)$ infectious diseases in the past month, $(B)$ urethral/vaginal discharge or genital sores in the past

12 months; and (C) the delay between experiencing urethral/vaginal discharge or genital sores and seeking assistance in the past 12 months.
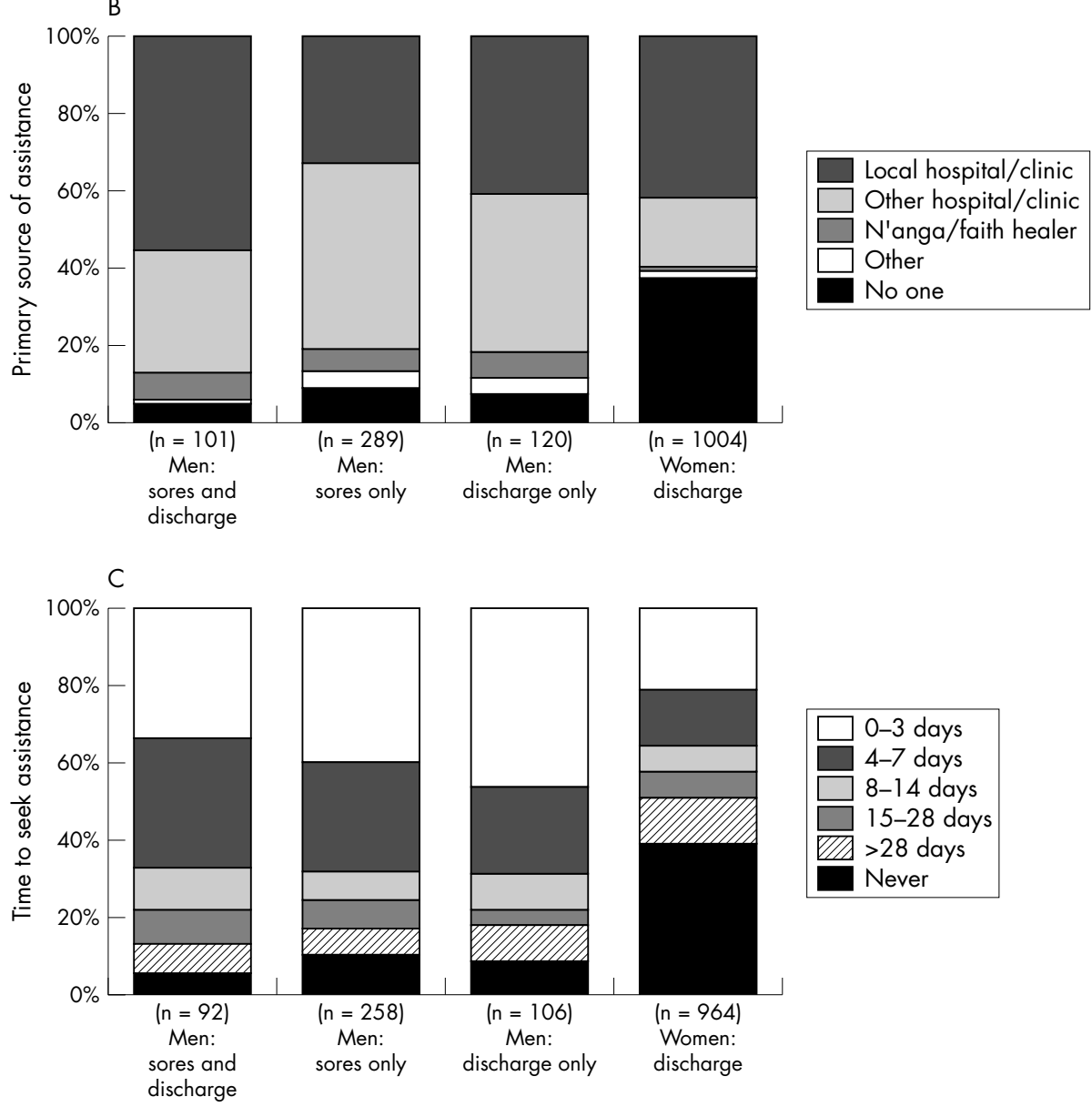

employment and those who lived in towns or estates were more likely to have sought treatment ( $\mathrm{p}$ values $<0.001$ ).

The sociodemographics that were predictive of time to seek treatment closely mirrored those found to be significant in predicting whether treatment was sought or not, as given in table 1. Those who had sought treatment tended to seek treatment relatively quickly. This could allow those who had yet to seek treatment, regarded as censored at 6 months, to polarise the distribution of time to seek treatment into those who sought treatment versus those who did not. Hence, the analysis was repeated, including only those who had sought treatment. For men, this resulted in all univariate associations with time to seek treatment being non-significant, while for women only age and availability of drugs were significant $(\mathrm{p}$ values $=0.006,0.039$ respectively). Younger women took longer to seek treatment, as did those who did not know whether STI drugs were available in local clinics.

Of the 968 people (17-44 years) who sought treatment for STIs at a hospital/clinic, 55\% were "very satisfied" with the service received, $23 \%$ "reasonably satisfied," and $22 \%$ "not satisfied." Women reported "very satisfied" less frequently than men $(47 \%$ to $66 \%$, p value $<0.001$ ), as did those who went to a local hospital/clinic rather than a different hospital/ clinic for both women and men separately ( $\mathrm{p}$ values $=0.044$, $0.005)$. Women who went to a local hospital/clinic were less likely to be "very satisfied" if they were from a subsistence farming area or roadside business centre, than if they were from an estate or a town $(\mathrm{p}$ value $=0.011)$. 
Table 1 Determinants of seeking any form of treatment for STI symptoms (urethral/vaginal discharge or genital sores in men) in the past year for sexually active men and women

\begin{tabular}{|c|c|c|c|c|c|c|c|}
\hline \multirow[b]{2}{*}{$\begin{array}{l}\text { Sociodemographic } \\
\text { characteristic }\end{array}$} & \multirow[b]{2}{*}{ Categories } & \multicolumn{3}{|c|}{ Men (17-54 years) } & \multicolumn{3}{|c|}{ Women (15-44 years) } \\
\hline & & $\begin{array}{l}\% \text { sought } \\
\text { treatment (n) }\end{array}$ & $\begin{array}{l}\text { Univariate } \\
\text { p value* }^{*}\end{array}$ & $\begin{array}{l}\text { Multivariate } \\
\text { p value* }\end{array}$ & $\begin{array}{l}\% \text { sought } \\
\text { treatment (n) }\end{array}$ & $\begin{array}{l}\text { Univariate } \\
\text { p value* }\end{array}$ & $\begin{array}{l}\text { Multivariate } \\
\text { p value* }\end{array}$ \\
\hline Symptom in past year & $\begin{array}{l}\text { Sores only } \\
\text { Discharge only } \\
\text { Sores and discharge }\end{array}$ & $\begin{array}{l}91.7 \%(327) \\
92.9 \%(127) \\
95.4 \%(109)\end{array}$ & 0.449 & 0.467 & & & \\
\hline Age category & $\begin{array}{l}15-16 \text { years } \\
17-24 \text { years } \\
25-34 \text { years } \\
35-44 \text { years } \\
45-54 \text { years }\end{array}$ & $\begin{array}{l}85.3 \%(143) \\
95.2 \%(231) \\
95.3 \%(128) \\
95.1 \%(61)\end{array}$ & 0.003 & 0.008 & $\begin{array}{l}42.9 \%(14) \\
56.7 \%(282) \\
69.3 \%(384) \\
63.7 \%(306)\end{array}$ & 0.004 & 0.126 \\
\hline Education & $\begin{array}{l}\text { None/primary } \\
\text { Secondary/higher }\end{array}$ & $\begin{array}{l}93.3 \%(224) \\
92.3 \%(339)\end{array}$ & 0.664 & 0.975 & $\begin{array}{l}63.4 \%(503) \\
63.8 \%(483)\end{array}$ & 0.909 & 0.527 \\
\hline Employment & $\begin{array}{l}\text { Unemployed } \\
\text { Employed }\end{array}$ & $\begin{array}{l}94.0 \%(100) \\
92.3 \%(431)\end{array}$ & 0.568 & 0.418 & $\begin{array}{l}58.9 \%(528) \\
69.0 \%(436)\end{array}$ & 0.001 & 0.013 \\
\hline Study area & $\begin{array}{l}\text { Estate } \\
\text { SFA† } \\
\text { Town } \\
\text { RBC }\end{array}$ & $\begin{array}{l}91.3 \%(218) \\
91.0 \%(134) \\
96.4 \%(139) \\
93.1 \%(72)\end{array}$ & 0.285 & 0.136 & $\begin{array}{l}71.2 \%(139) \\
59.2 \%(439) \\
76.1 \%(180) \\
57.5 \%(228)\end{array}$ & $<0.001$ & 0.001 \\
\hline \multirow[t]{2}{*}{ Marital status } & $\begin{array}{l}\text { Never married } \\
\text { Currently married }\end{array}$ & $\begin{array}{l}88.6 \%(175) \\
95.2 \%(332)\end{array}$ & \multirow[t]{2}{*}{0.026} & \multirow[t]{2}{*}{0.425} & $\begin{array}{l}56.0 \%(75) \\
62.9 \%(666)\end{array}$ & \multirow[t]{2}{*}{0.149} & \multirow[t]{2}{*}{0.920} \\
\hline & \multicolumn{2}{|c|}{$\begin{array}{l}\text { Currently separated, divorced, } 91.1 \% \text { (56) } \\
\text { or widowed }\end{array}$} & & & $67.8 \%(245)$ & & \\
\hline $\begin{array}{l}\text { Time outside community in } \\
\text { past year }\end{array}$ & $\begin{array}{l}<1 \text { month } \\
\geqslant 1 \text { month }\end{array}$ & $\begin{array}{l}94.5 \%(183) \\
91.8 \%(380)\end{array}$ & 0.252 & 0.053 & $\begin{array}{l}60.2 \%(299) \\
65.2 \%(686)\end{array}$ & 0.137 & 0.624 \\
\hline $\begin{array}{l}\text { Are STIs co-factor for HIV } \\
\text { transmission?§ }\end{array}$ & $\begin{array}{l}\text { Yes, spontaneous } \\
\text { Yes, prompted } \\
\text { No, prompted } \\
\text { Don't know, prompted }\end{array}$ & $\begin{array}{l}91.3 \%(69) \\
93.6 \%(407) \\
91.5 \%(59) \\
85.7 \%(28)\end{array}$ & 0.436 & 0.317 & $\begin{array}{l}65.2 \%(46) \\
62.3 \%(709) \\
78.9 \%(76) \\
61.2 \%(152)\end{array}$ & 0.041 & 0.188 \\
\hline $\begin{array}{l}\text { Number of lifetime sexual } \\
\text { partners }\end{array}$ & $\begin{array}{l}1 \\
2-3 \\
4-10 \\
>10\end{array}$ & $\begin{array}{l}84.2 \%(19) \\
90.9 \%(88) \\
93.2 \%(280) \\
94.6 \%(166)\end{array}$ & 0.350 & 0.805 & $\begin{array}{l}59.9 \%(538) \\
65.3 \%(303) \\
75.0 \%(100) \\
72.0 \%(25)\end{array}$ & 0.020 & 0.431 \\
\hline $\begin{array}{l}\text { Are STI drugs available in } \\
\text { local clinics? }\end{array}$ & $\begin{array}{l}\text { Yes } \\
\text { No } \\
\text { Don't know }\end{array}$ & $\begin{array}{l}93.9 \%(181) \\
95.7 \%(161) \\
89.3 \%(215)\end{array}$ & 0.055 & 0.028 & $\begin{array}{l}86.8 \%(303) \\
76.2 \%(164) \\
45.2 \%(507)\end{array}$ & $<0.001$ & $<0.001$ \\
\hline \multicolumn{8}{|c|}{$\begin{array}{l}\text { *Logistic regressions. } \\
\text { tSubsistence farming areas. } \\
\text { †Roadside business centres. } \\
\text { \$Respondents were asked to name any factors which could increase the chances of a person becoming infected with HIV/AIDS. Then a list of possibilities that had } \\
\text { not been named was mentioned and respondents were asked to agree or disagree with each in turn. }\end{array}$} \\
\hline
\end{tabular}

\section{DISCUSSION}

This study provides a detailed examination of the age and gender specific patterns of HIV infection and self reported STI symptoms among 9480 adults in rural Manicaland, Zimbabwe. Experience of STI symptoms and HIV infection were both very common in this population, consistent with other studies of the prevalence of STIs and related symptoms. ${ }^{77-19}$ The majority of both men and women sought treatment for STIs and other infectious diseases from hospitals or clinics, with very few reporting treatment from pharmacies, n'angas, or faith healers.

The gender differences in treatment seeking were broadly similar to those seen in a study in Nairobi, Kenya. ${ }^{20}$ Structural factors provide one explanation: women were less satisfied with received STI treatment than men, possibly reflecting greater stigmatisation faced by women seeking STI treatment, but were then less likely to seek treatment elsewhere, possibly because they were less mobile than men. Alternatively, if women regard the discharge as unrelated to STIs, which given prevalence of bacterial vaginosis of 33\% in the rural growth point survey ${ }^{17}$ may be reasonable, they may not seek treatment. This would still be worrying, given the positive association between bacterial vaginosis and HIV infection. ${ }^{21} 22$

In understanding our results two questions need to be addressed about self reported symptoms. Firstly, the extent to which they capture the distribution of STI signs and second the underlying aetiology of infections associated with the prevalent signs and symptoms. The pilot study found that none of the men reporting genital ulcers were positive for syphilis, but eight out of 10 men with current or past symptoms were HSV-2 positive. $^{7}$ Less than $3 \%$ of those reporting recent urethral/vaginal discharge were positive for gonorrhoea or chlamydia, but 24 of 48 had trichomoniasis antibodies. Further work on trichomoniasis found $9.1 \%$ of 3478 women with no history of discharge were seropositive, compared to $11.8 \%$ of 1115 women who reported discharge in the past year $(\mathrm{p}$ value $=0.007){ }^{23}$ This suggests that STI symptoms represent an important, but imprecise marker of STI infection. While of interest in the use of STI treatment as an HIV control strategy, ${ }^{24}$ this does not impact on the analysis of treatment seeking behaviour as this behaviour is driven by symptoms not by aetiology. Although lower abdominal pain is a common symptom of several STIs, it was considered to be a non-specific symptom and more open to recall bias than discharge or sores and hence was excluded from all analyses. This may have led to an underestimation of STI symptoms in this study. The very broad categorisation of medical complaint as STIs or other infectious diseases should be robust in reflecting people's beliefs about the causes of their disease, unless more than one medical complaint was experienced that month. Although reported satisfaction with the service received in hospitals/clinics is likely to be an imprecise measure of successful STI treatment, crucially it provides information on the perception of these health services in this area.

The Government of Zimbabwe Poverty Assessment survey in 1995, asked 16000 respondents where they sought 
treatment for any illness in the past month: $58 \%$ went to a public facility, $7 \%$ to a private clinic or hospital, $1 \%$ to a traditional healer, $1 \%$ to some other form of healer, and $32 \%$ sought no treatment. ${ }^{2}$ Private consultation was five times more common in urban areas than rural areas. These results are broadly similar to those found in this study. However, a study in Zimbabwe of 457 men from Gutu (rural town) and Mbare (urban district of Harare) found that $21.6 \%$ reported sometimes visiting traditional healers when ill. ${ }^{19}$ Additionally, of 220 reported cases of genital symptoms, $81.4 \%$ were treated by allopathic practitioners, $9 \%$ by traditional/faith healers, and $8.6 \%$ by the respondent, a friend, or another person. The high reliance on traditional healers suggested in this study, compared to the results from both our study and the poverty assessment survey, may be because people tried a variety of healthcare providers and only reported the predominant or most socially acceptable one. Some people visit a medical doctor for treatment of the symptoms and then a n'anga or faith healer for eradication of the underlying problem, termed a spiritual cure. Hence, a possible weakness of our study was the recording of one source of treatment only, which may have led to underreporting of visits to n'angas and faith healers by people who also went to a hospital/clinic.

There was a strong association for men between lifetime sexual behaviour and experience of symptoms. However, almost a third of women reporting one lifetime partner had experienced discharge. This was much higher than seen in men and could be because of under-reporting of number of partners by women. Some reported discharge in women could be a result of bacterial vaginosis, which is not sexually transmitted, but for which sexual intercourse is a risk factor ${ }^{25}$; this was detected in $33 \%$ of women in the national survey of rural growth points. ${ }^{17}$ Alternatively, a woman's risk may depend more on her partner' s behaviour than her own, so that many women are at risk with only one partner.

The effectiveness of treatment in these hospitals/clinics, both in terms of success in directly treating the infection and in the prevention of re-infection through counselling, remains unknown. The issues that caused $22 \%$ to report they were "not satisfied" with treatment were not recorded. Over a third of women had not sought treatment for vaginal discharge; whether this was because they regarded it as normal or was the result of poor access to treatment is extremely important in informing STI treatment strategies.

This study has shown that a high percentage of this rural population have experienced the symptoms of urethral/ vaginal discharge and genital sores in their lifetime. Following the appearance of these symptoms, treatment seeking is common and relatively quick among men, less so among women. The reduction of delays in seeking treatment, particularly among women, must be a priority. However, in the absence of screening and diagnostic tests only symptomatic infections will be treated, with a substantial asymptomatic epidemic remaining. Such infections will only be controlled in a resource poor setting by changes in risk behaviours or improved methods of case finding.

\section{ACKNOWLEDGEMENTS}

We thank the Medical Research Council, UK (JJCL and GPG), the Wellcome Trust (GPG, CAN and SG), CDC (GPG and SG), the Royal Society (GPG) and UNAIDS (GPG and SG) for funding support. We also thank Ruanne Barnabas for the categorising of illness symptoms.

\section{CONTRIBUTORS}

Data collection was designed and supervised by SG and CAN, with technical support from PRM, GPG, and CAD; this analysis of the data was conceived and carried out by JJCL, who also drafted the manuscript; critical revision of the manuscript and interpretation of the analysis was conducted by all.

\section{Key messages}

- Where syndromic management is a key intervention for STls the treatment seeking behaviour will have a large impact on STI control. We show that in Zimbabwe clinics and hospitals are the main source of health care as opposed to informal or traditional venues

- For STI related symptoms treatment is sought rapidly by most men, whereas many women fail to seek care

- Patterns of satisfaction with treatment services along with lower rates of attending clinics in distant locations by women compared to men suggest that women seek care less frequently because of stigma and lack of mobility

\section{Authors' affiliations}

J J C Lewis, G P Garnett, C A Nyamukapa, C A Donnelly, S Gregson, Department of Infectious Disease Epidemiology, Imperial College London, Faculty of Medicine, St Mary's Campus, Norfolk Place, London W2 IPG, UK

P R Mason, C A Nyamukapa, S Gregson, Biomedical Research and Training Institute, University of Zimbabwe Campus, PO Box CY 1753, Causeway, Harare, Zimbabwe

Conflicts of interest: Funding from Medical Research Council, UK; the Wellcome Trust; CDC; the Royal Society; UNAIDS.

Ethical approvals: Previous ethical approval for the study was obtained from the Research Council of Zimbabwe (Number 02187) and from the St Mary's local research ethics committee, London (HIV/GUM EC no 03.66 R\&D 03/SB/004E).

\section{REFERENCES}

1 UNAIDS. AIDS epidemic update 2003.

2 Decosas J, Padian N. The profile and context of the epidemics of sexually transmitted infections including HIV in Zimbabwe. Sex Transm Infect 2002;78(Suppl 1):i40-6.

3 UNAIDS. Report on the global HIV/AIDS epidemic 2002

4 Latif AS, Katzenstein DA, Bassett MT, et al. Genital ulcers and transmission of HIV among couples in Zimbabwe. AIDS 1989;3:519-23.

5 Rottingen JA, Cameron DW, Garnett GP. A systematic review of the epidemiologic interactions between classic sexually transmitted diseases and HIV: how much really is known? Sex Transm Dis 2001;28:579-97.

6 Gregson S, Terceira N, Kakowa M, et al. Study of bias in antenatal clinic HIV1 surveillance data in a high contraceptive prevalence population in subSaharan Africa. Aids 2002;16:643-52.

7 Gregson S, Mason PR, Garnett GP, et al. A rural HIV epidemic in Zimbabwe? Findings from a population-based survey. Int J STD AIDS 2001;12:189-96.

8 Garnett GP, Bowden FJ. Epidemiology and control and curable sexually transmitted diseases: opportunities and problems. Sex Transm Dis 2000;27:588-99.

9 Dallabetta GA, Gerbase AC, Holmes KK. Problems, solutions, and challenges in syndromic management of sexually transmitted diseases. Sex Transm Infect 1998;74(Suppl 1):S1-11.

10 Aral SO, Wasserheit JN. STD related health care seeking and health service delivery. In: Holmes KK, Mardh P-A, Sparling PF, et al. In: Sexually transmitted diseases.3rd ed. New York: McGraw-Hill, 1999:1295-305.

11 Sherrard J, Barlow D. Gonorrhoea in men: clinical and diagnostic aspects. Genitourin Med 1996;72:422-6.

12 Garnett GP, Mertz KJ, Finelli L, et al. The transmission dynamics of gonorrhoea: modelling the reported behaviour of infected patients from Newark, New Jersey. Philos Trans R Soc Lond B Biol Sci 1999;354:787-97.

13 Buve A, Changalucha J, Mayaud P, et al. How many patients with a sexually transmitted infection are cured by health services? A study from Mwanza region, Tanzania. Trop Med Int Health 2001;6:971-9.

14 Paxton LA, Kiwanuka N, Nalugoda F, et al. Community based study of treatment seeking among subjects with symptoms of sexually transmitted disease in rural Uganda. Bmi 1998;317:1630-1.

15 Gregson S, Zhuwau T, Ndlovu J, et al. Methods to reduce social desirability bias in sex surveys in low-development settings: experience in Zimbabwe. Sex Transm Dis 2002;29:568-75.

16 Ray CS, Mason PR, Smith H, et al. An evaluation of dipstick-dot immunoassay in the detection of antibodies to HIV-1 and 2 in Zimbabwe. Trop Med Int Health 1997;2:83-8.

17 Woelk GB, Kasprzyk D, Montano DE, et al. National survey of STDs and HIV prevalence among residents in rural growth point villages in Zimbabwe. In:XIV International AIDS Conference.Barcelona, 2002. 
18 Montano DE, Kasprzyk D, Woelk G. National survey of behavioral risk for STDs and HIV among residents in rural growth point villages in Zimbabwe. In:XIV International AIDS Conference.Barcelona, 2002.

19 Gibney L, Chikukwa P, Seidenberg P, et al. STD treatment for men in rural and urban Zimbabwe: choice of practitioner, perceptions of access and quality of care. Int J STD AIDS 2002;13:201-9.

20 Voeten HA, O'Hara HB, Kusimba J, et al. Gender differences in health care seeking behavior for sexually transmitted diseases: a population-based study in Nairobi, Kenya. Sex Transm Dis 2004;31:265-72.

21 Sewankambo N, Gray RH, Wawer MJ, et al. HIV-1 infection associated with abnormal vaginal flora morphology and bacterial vaginosis. Lancet 1997;350:546-50
22 Mbizvo EM, Msuya SE, Stray-Pedersen B, et al. HIV seroprevalence and its associations with the other reproductive tract infections in asymptomatic women in Harare, Zimbabwe. Int J STD AIDS 2001;12:524-31.

23 Mason PR, Fiori PL, Cappuccinelli P, et al. Seroepidemiology of Trichomonas vaginalis in rural women in Zimbabwe and patterns of association with HIV infection. (submitted).

24 Grosskurth H, Gray R, Hayes R, et al. Control of sexually transmitted diseases for HIV-1 prevention: understanding the implications of the Mwanza and Rakai trials. Lancet 2000;355:1981-7.

25 Mbizvo EM, Msuya SE, Stray-Pedersen B, et al. Determinants of reproductive tract infections among asymptomatic women in Harare, Zimbabwe. Cent Afr J Med 2001;47:57-64.

\section{Clinical Evidence - Call for contributors}

Clinical Evidence is a regularly updated evidence-based journal available worldwide both as a paper version and on the internet. Clinical Evidence needs to recruit a number of new contributors. Contributors are healthcare professionals or epidemiologists with experience in evidence-based medicine and the ability to write in a concise and structured way.

Areas for which we are currently seeking authors:

- Antenatal monitoring

- Dietary supplementation and treatments in pregnancy

- Palliative care

- Prolonged pregnancy

We are also looking for authors for existing topics. For full details on what these chapters are please visit www.clinicalevidence.com/ceweb/contribute/index.jsp

However, we are always looking for others, so do not let this list discourage you.

Being a contributor involves:

- Selecting from a validated, screened search (performed by in-house Information Specialists) epidemiologically sound studies for inclusion.

- Documenting your decisions about which studies to include on an inclusion and exclusion form, which we keep on file.

- Writing the text to a highly structured template (about 1500-3000 words), using evidence from the final studies chosen, within 8-10 weeks of receiving the literature search.

- Working with Clinical Evidence editors to ensure that the final text meets epidemiological and style standards.

- Updating the text every 6 months using any new, sound evidence that becomes available. The Clinical Evidence in-house team will conduct the searches for contributors; your task is simply to filter out high quality studies and incorporate them in the existing text.

- To expand the topic to include a new question about once every 12-18 months.

If you would like to become a contributor for Clinical Evidence or require more information about what this involves please send your contact details and a copy of your CV, clearly stating the clinical area you are interested in, to CECommissioning@bmigroup.com.

Call for peer reviewers

Clinical Evidence also needs to recruit a number of new peer reviewers specifically with an interest in the clinical areas stated above, and also others related to general practice. Peer reviewers are healthcare professionals or epidemiologists with experience in evidence-based medicine. As a peer reviewer you would be asked for your views on the clinical relevance, validity, and accessibility of specific topics within the journal, and their usefulness to the intended audience (international generalists and healthcare professionals, possibly with limited statistical knowledge). Topics are usually 1500-3000 words in length and we would ask you to review between 2-5 topics per year. The peer review process takes place throughout the year, and out turnaround time for each review is ideally 10-14 days.

If you are interested in becoming a peer reviewer for Clinical Evidence, please complete the peer review questionnaire at www.clinicalevidence.com/ceweb/contribute/peerreviewer.jsp 